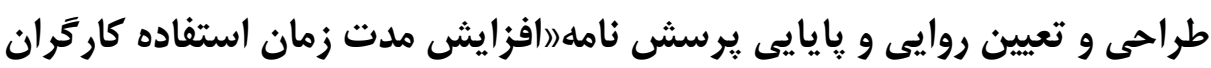

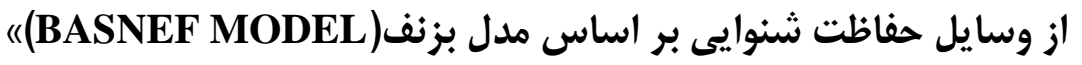

\author{
محمدر ضا منظم'، فريدون لعل"، ولى سرسنگى"' روح اله فلاح مدوارى *؛ كامران نجفى' على رضا فلاح مدوارى؛
}

() كروه مهندسى بهداشت حرفهاى، درنشكده بهداشت، درنشكاه علوم يزشكى تهرلن، إيران

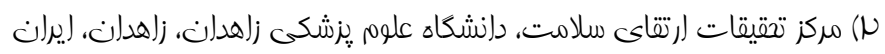

مار) كميته تققيقات دانشجويى، دلنشكده بهداشت، دانشكاه علوم يزشكى كناباد، كناباد، إيرلن

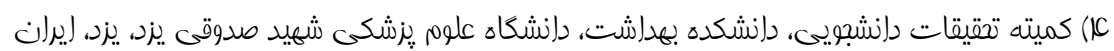
تاريخ هذيرش: ع $90 / 2$
تاريخ دريافت:

مقدمه: بعد از كنترل فنى مهندسى و مديريتى صدا، آخرين راه كنترل صدا استفاده از كَشى حفاظتى مى باشد كه كارايى آن

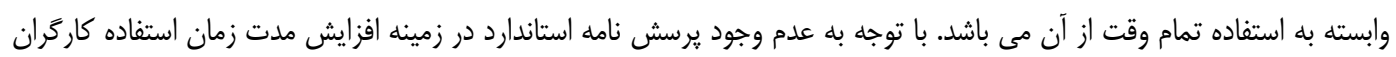

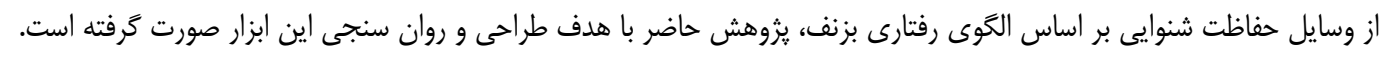

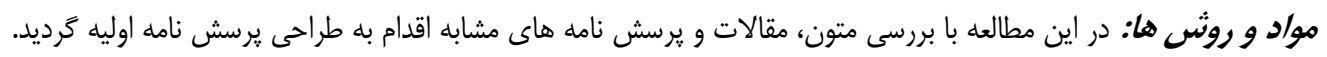

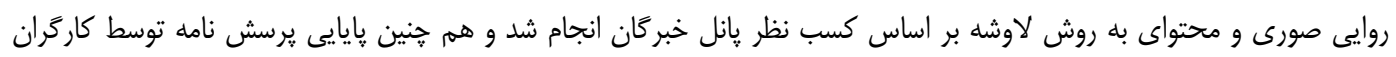

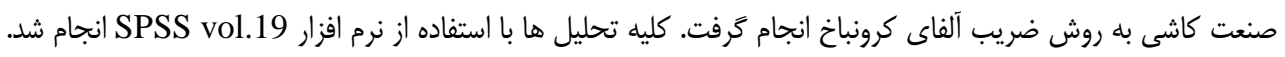

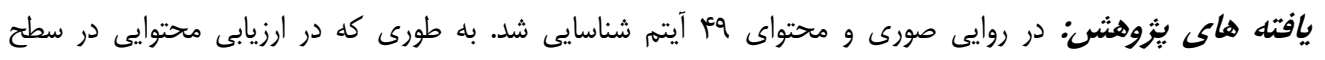

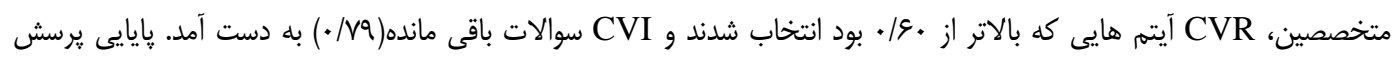

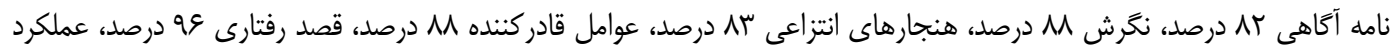

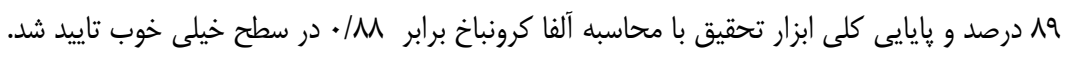

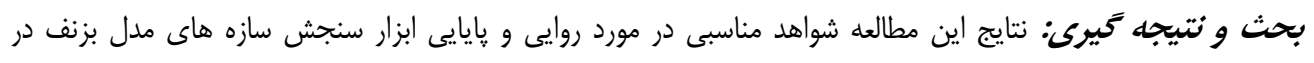
افزايش مدت زمان استفاده از گوشى هاى محافظ شنوايى را فراجه اهم نمود.

وازه هاى كليدى: مدل بزنف، روايى - يايايى يرسش نامه، وسايل حفاظت شنوايى، صنعت كاشى

*ُنويسنده مسئول: كميته تحقيقات دانشجويى، دانشكده بهداشت، دانشخاه علوم يزشكى شهيد صدوقى يزد، يزد، ايران

Email: Fallah134@yahoo.com

Copyright (c) 2017 Journal of Ilam University of Medical Science. This is an open-access article distributed under the terms of the Creative Commons Attribution international 4.0 International License (https://creativecommons.org/licenses/by-nc/4.0/) which permits copy and redistribute the material, in any medium or format, provided the original work is properly cited. 
مقايسه نماييم. يرسش نامه استاندارد در زمينه افزايش

مقدمه

مدت زمان استفاده كارگران از وسايل حفاظت شنوايى

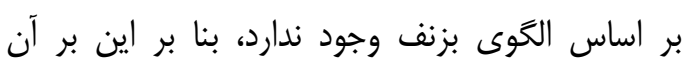

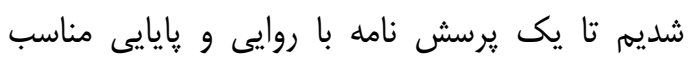
طراحى نماييم.

\section{مواد و روش ها نماين}

اين مطالعه، يك بررسى توصيفى تحليلى است.

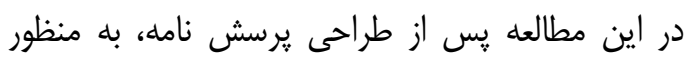
بررسى روايى و يايايى به ترتيب مراحل زير انجام شد:

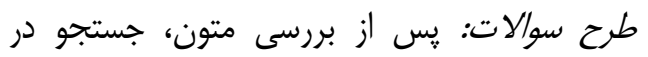

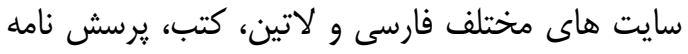

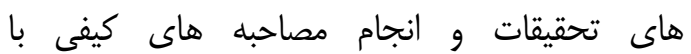

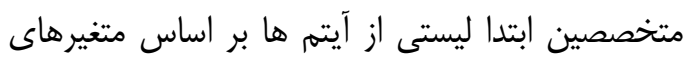
مدل آموزشى بزنف طراحى شد.

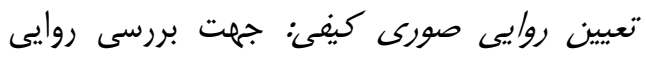

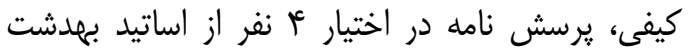

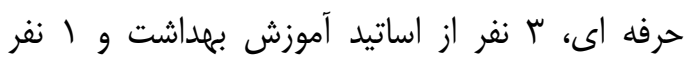

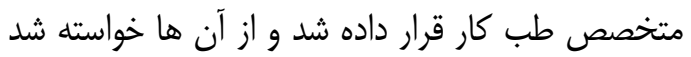
تا نظرات خود را در خصوص يرسش نامه و خصوصيات ظاهرى آن بيان نمايند. يس از انجام سه مر حله اصله بلاح اقدام به طراحى و تدوين ابزار مورد نظر كرديد.

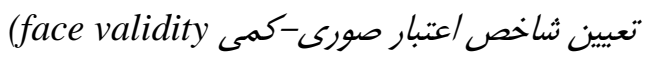
(index) كمى :رسش نامه، ليست كاملى از آيتم هاى تدوين

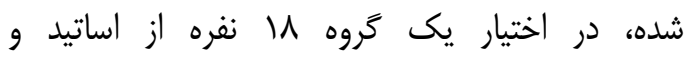
دانشجويان Ph.D رشته بهداشت حرفه اى و آموزش

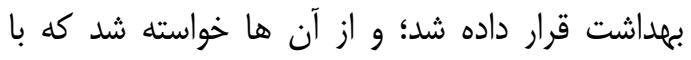
توجه به هدف تحقيق كه "ابررسى تاثير مداخله آموزشى بر اساس مدل بزنف (BASNEF Model) در افزايش مدت زمان استفاده كاركران از كوشى مولف حفاظتى" در مورد ظاهر يرسش نامه به صورت "امرتبط

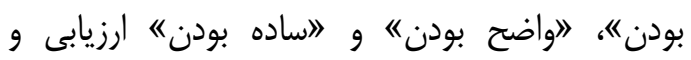
اظهارنظر كنند. هر كدام از سوالات مربوط به به هر فاكتور به صورت تفكيك شده در جداولى همانند جدول شماره ا در اختيار \\ نفر از متخصصين قرار داده شد و از آن آن

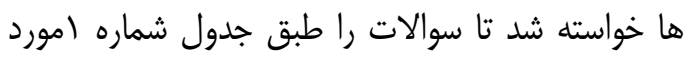

ارزيابى قرار دهند(19).
سر و صدا يكى از عوامل زيان آور موجود در محيط

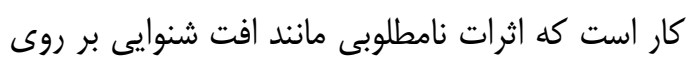

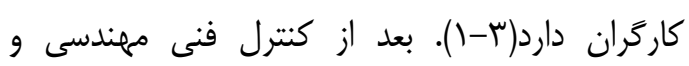

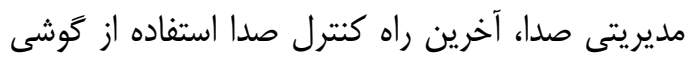

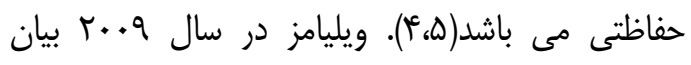

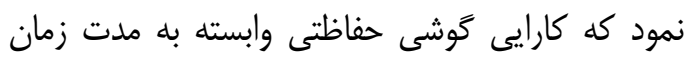

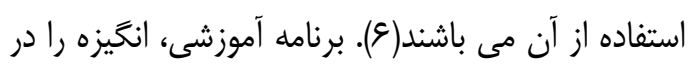

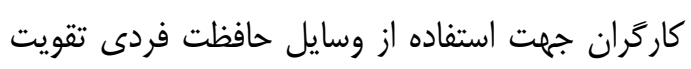

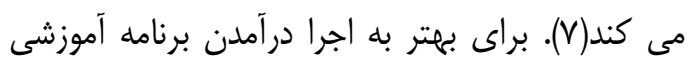

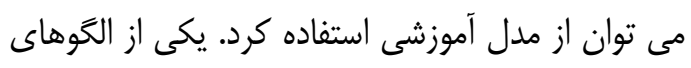

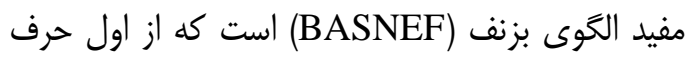

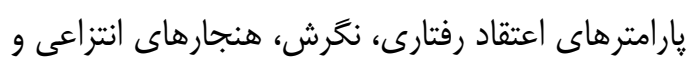

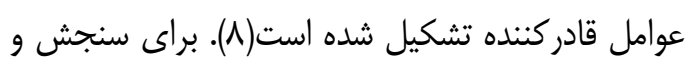

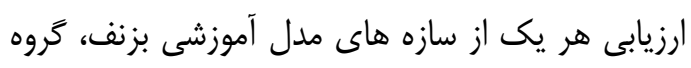

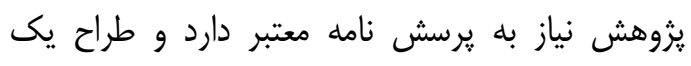

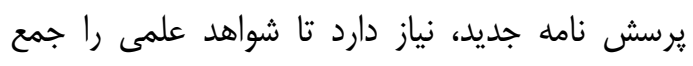

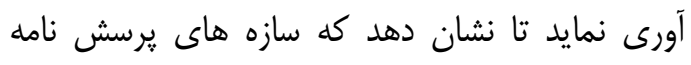
طراحى شده از روايى و محتوايى مناسبى برخوردار نار داري است(·) (9). روايى، مقدار خطاى سيستماتيك يا ايجاد

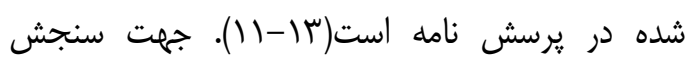

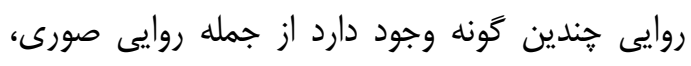

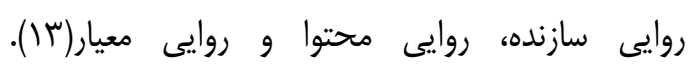

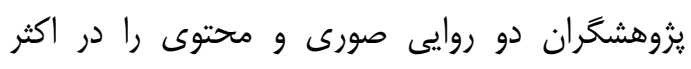

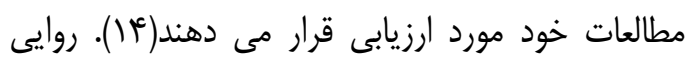
صورى زمانى ايجاد مى شود كه محقق، مشخصه يا

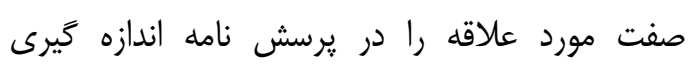

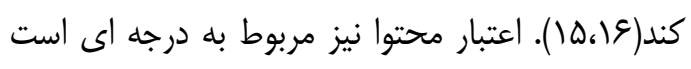

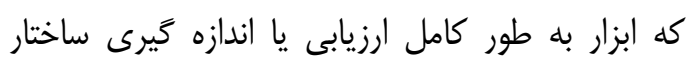

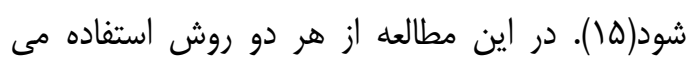

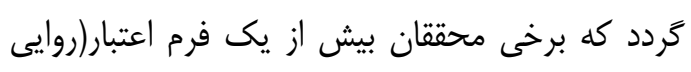

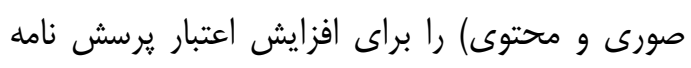

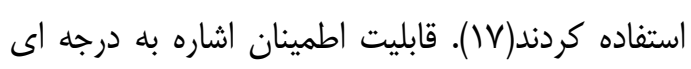

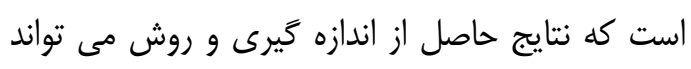

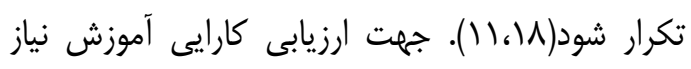

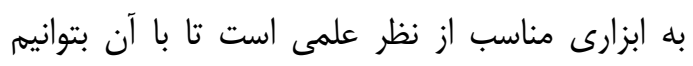

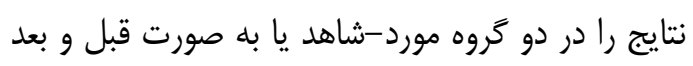


جدول شماره ا. تعيين روايى صورى

\begin{tabular}{|c|c|c|c|c|c|c|c|c|c|c|c|c|}
\hline \multicolumn{4}{|c|}{ ساده بودن } & \multicolumn{4}{|c|}{ واضح بودن } & \multicolumn{4}{|c|}{ مرتبط بودن } & \multirow[b]{2}{*}{ عنوان سوال } \\
\hline 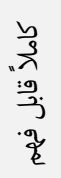 & $\begin{array}{l}3: \\
3 \\
\vdots \\
\vdots \\
3 \\
\vdots \\
2\end{array}$ & 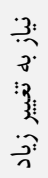 & $\begin{array}{l}\text { y: } \\
\text { :- } \\
\text { :के } \\
\text { के } \\
\text { है }\end{array}$ & रे & $\begin{array}{l}3: \\
3 \\
2 \\
\vdots 3 \\
3 \\
2 \\
2\end{array}$ & 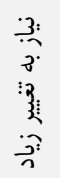 & \&. & $\begin{array}{c}\frac{2}{3} \\
3 \\
3 \\
3 \\
3\end{array}$ & $\begin{array}{l}3: \\
3 \\
\vdots \\
\vdots \\
\vdots \\
y_{2}\end{array}$ & 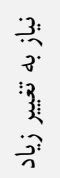 & $\begin{array}{l}\dot{3} \\
3 \\
3 \\
3 \\
3\end{array}$ & \\
\hline & & & & & & & & & & & & 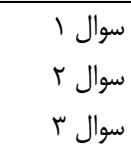 \\
\hline
\end{tabular}

فهزم بودن محاسبه شد. جنان جه سوالى درصد قابل قبول يكى از ارزيابى هايش زير • V درصد بود مورد

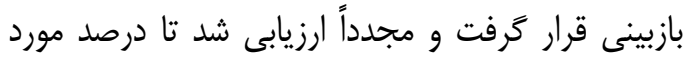

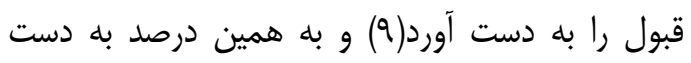

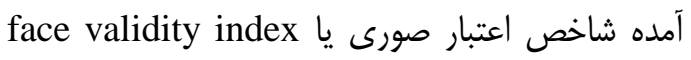
مى گويند.

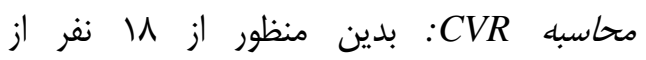
متخصصين فن درخواست شد تا در مورد اهميت و ضرورت هر كدام از سوالات زيرسش نامه اظهار نظر

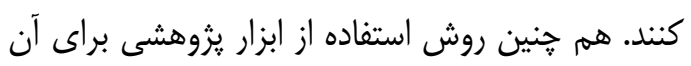

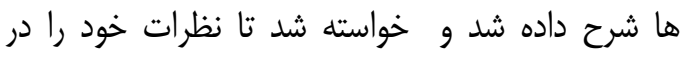
خصوص سوالات طبق جدول شماره r ارائه دهند(19).
در رابطه با معيار "ساده بودن" طيف ليكرت جهار

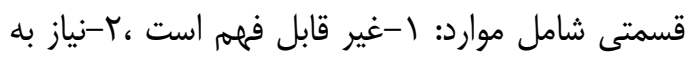

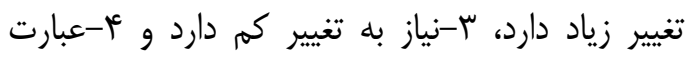
كاملاً قابل فهم است بود. در رابطه با معيار لامرتبط بودنه طيف ليكرت جهبار قسمتى شامل: ا-عبارت نا مرتبط است، r-عبارت نياز به تغيير زياد دارد، س-عبارت

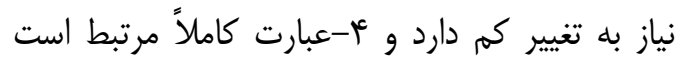

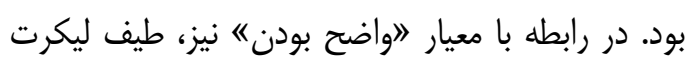

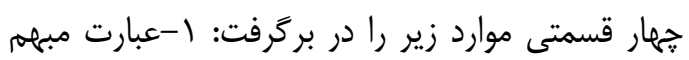
است، r-عبارت نياز به تغيير زياد دارد س-عبارت نياز به زيه

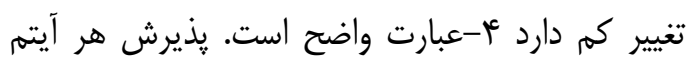
بر اساس معيار زير صورت گرفت: براى هر سوال درصد

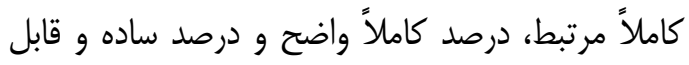

\begin{tabular}{|c|c|c|c|}
\hline \multicolumn{2}{|c|}{ جدول شماره ז. ارزيابى سوالات بـ روش لاوشه } & ارزشيابى متخصص از سوالات & \multirow[b]{2}{*}{ عنوان سوال } \\
\hline غير مرتبط & مى اما ضراند استفاده شود & مهمم و مرتبط & \\
\hline & & & سوال 1 \\
\hline & & & 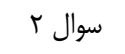 \\
\hline & & & 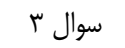 \\
\hline
\end{tabular}

CVR مى باشد كه گزينه مهم و مرتبط را براى هر سوال

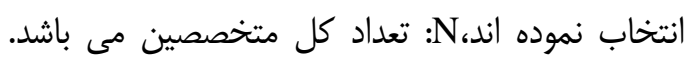
حداقل مقدار CVR قابل قبول براى هر سوال بر اساس تعداد متخصصانى كه در خصوص روايى محتوا

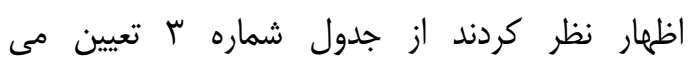

شود(19).
يس از جمع آورى نظرات براى ارزيابى شاخص نسبت روايى محتوا، CVR براى هر سوال طبق معادله

$$
\text { (محاسبه گرديد( آr، •r). }
$$

$C V R=\frac{n e-\frac{N}{2}}{\frac{N}{2}}$
معادله ) 
جدول شماره س. تعيين حداقل CVR قابل قبول بر اساس تعداد متخصصين اظهار نظر كرده

\begin{tabular}{|c|c|}
\hline حداقل CVR قابل قبول & تعداد متخصصين \\
\hline ./99 & $\Delta$ \\
\hline.$/ 99$ & $\varepsilon$ \\
\hline.$/ 99$ & $\checkmark$ \\
\hline$\cdot / \mathrm{VA}$ & $\wedge$ \\
\hline$\cdot / V \Delta$ & 9 \\
\hline . & 1. \\
\hline$\cdot 109$ & 11 \\
\hline$\cdot / \Delta F$ & it \\
\hline$\cdot / \& \Delta$ & 11 \\
\hline
\end{tabular}

مقايسه گرديد سبس آلفاى كرونباخ ابزار براى هر آيـتم به صورت جداكانه و به طور كلى محاسبه كرديد.

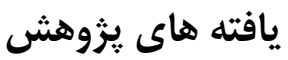

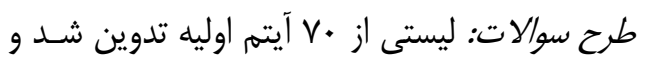
يس از حذف جملات مشابه و يا نامناسب(آب آيته)، بـا

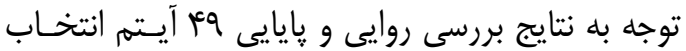

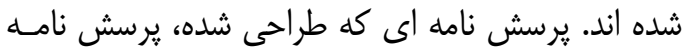

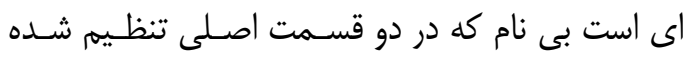

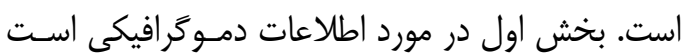
كه در خصوص مشخصات فردى شـامل ه سـوال مسى

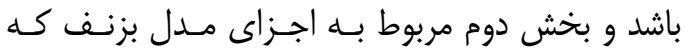

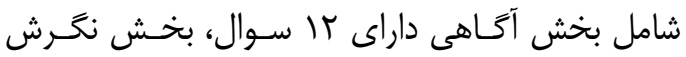

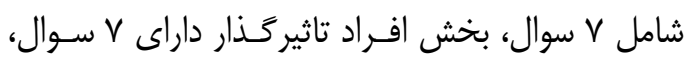

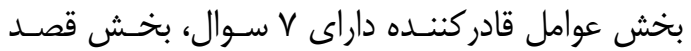

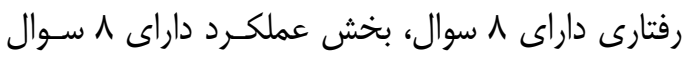

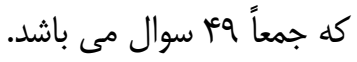

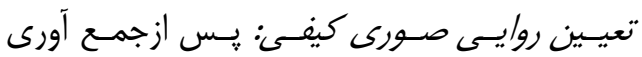
نظرات متخصصين در مورد خصوصيات ظاهرى يرسش

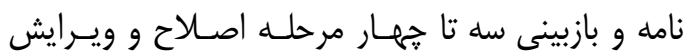

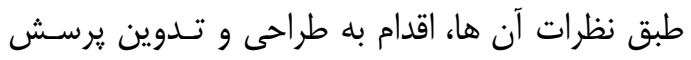
نامه نهايى مورد نظر كرديد.

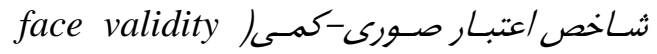
index

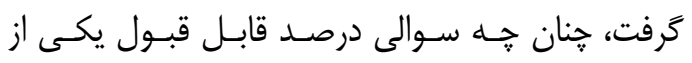

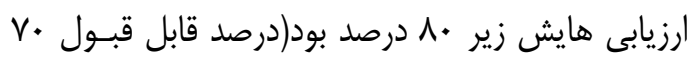

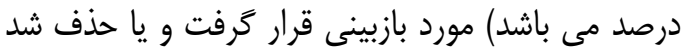

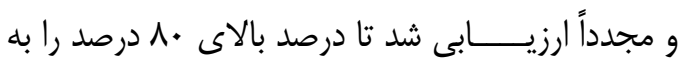

در اين مطالعه تعـداد متخصصـينى كـه اظهـارنظر

كردند \1 نفر مى باشند كه طبق جدول مقـدار

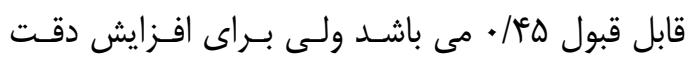

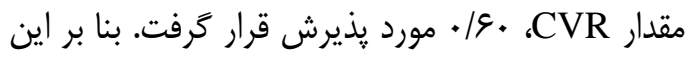
يرسـش هـايى كـه CVR بـالاتر از • •l/ داشـتند در يرسش نامه حفظ و بقيه حذف شدند.

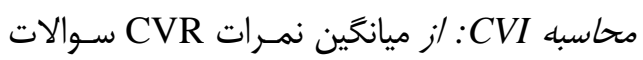

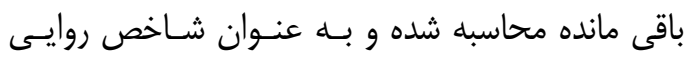

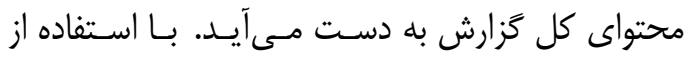

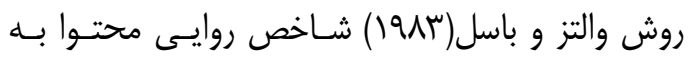

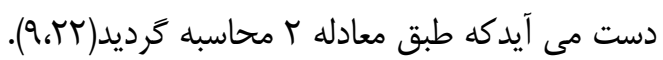

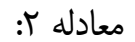
$C V I=\frac{\Sigma_{n}^{1} C V R}{\text { RETAINED NUMBERS }}$

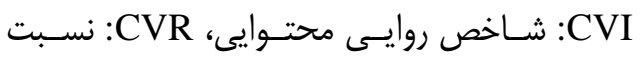

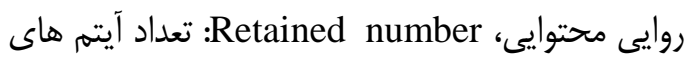
باقى مانده در اين روش سوال هاى داراى نمره بالاتر از Vو/.

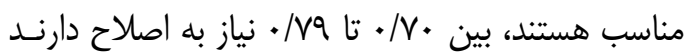

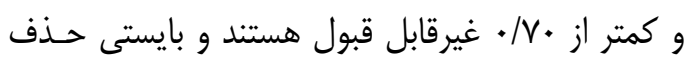
شوند(Tr). تعبين بإيايی(Reliability): براى تعيـين بايـايى از

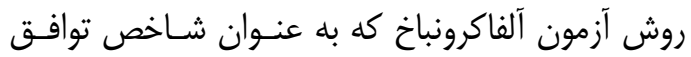

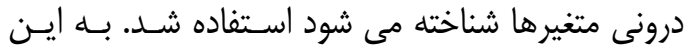

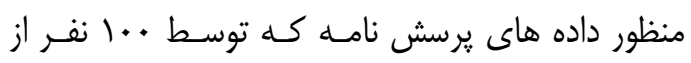

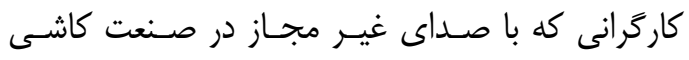

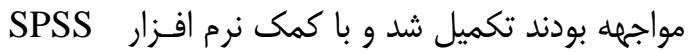
vol.19 به طور همسانى درونى(زوج و فرد) با يكـديخر 


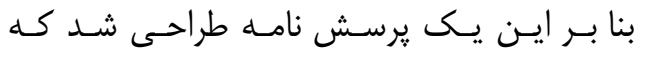
مقدار CVI يا شاخص روايى محتوايى آن مقـدار قابـل قبول(V9) • است.

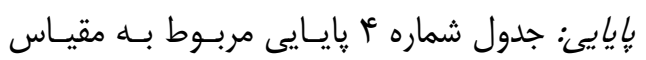

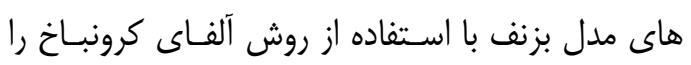

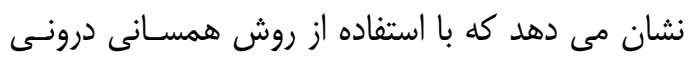

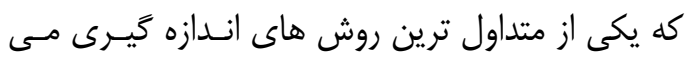

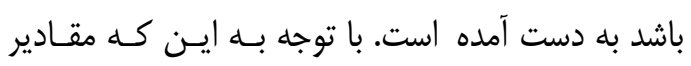

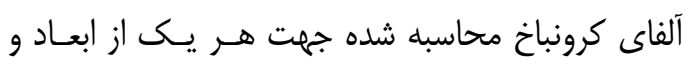

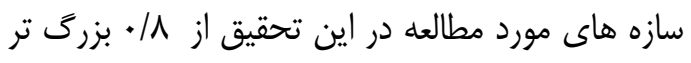

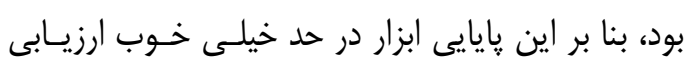
شده و مورد تائيد قرار كرفت.

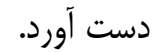

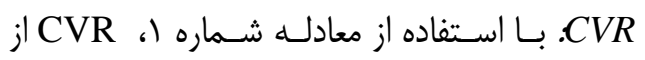
قضاوت اعضاى گروه براى هر سوال محاسبه كرديـــ و

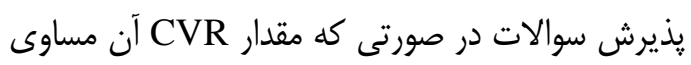

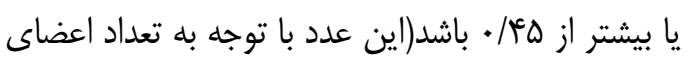

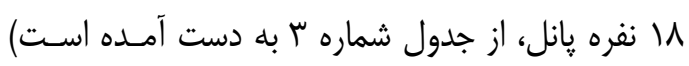

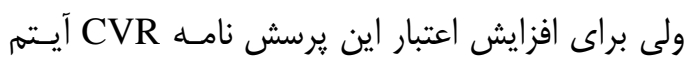
هايى كه بالاتر از \&/ • بود باقى ماندند. CVI r به دست آمد: - ( ) مقدار $C V I=\frac{38.71}{49}=0.79$

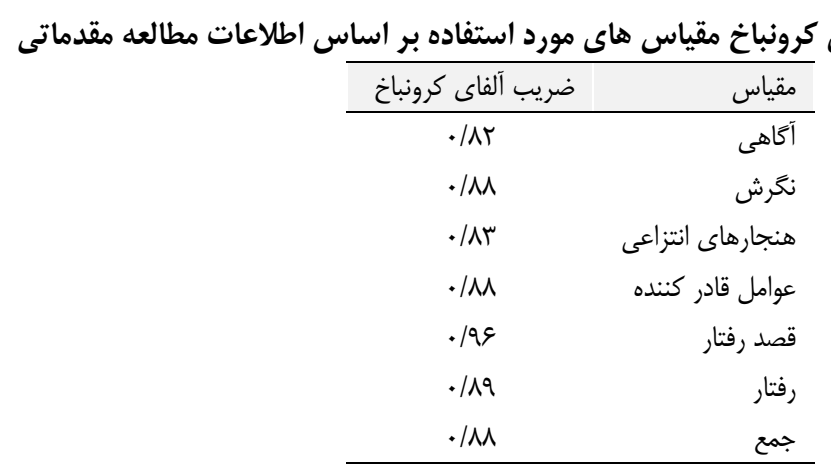

دهنده قابليت اعتماد بالاى اين ابزار سنجش مى باشد.

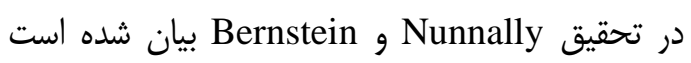

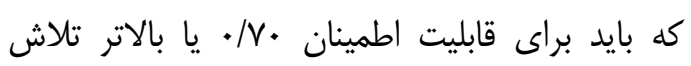

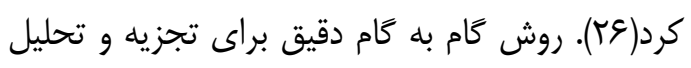

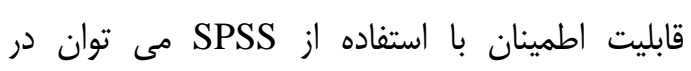

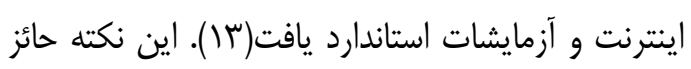

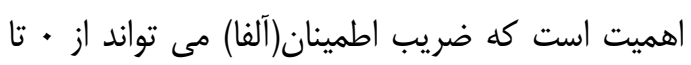

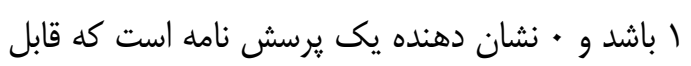

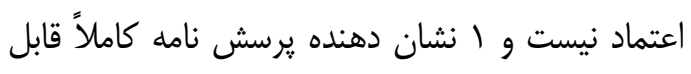

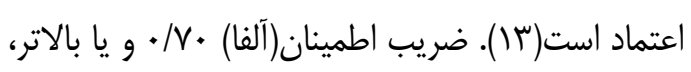
يايايى قابل قبول در SPSS محسوب مى شود(سار).

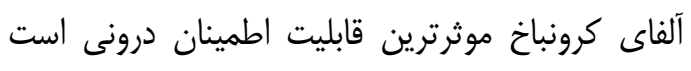

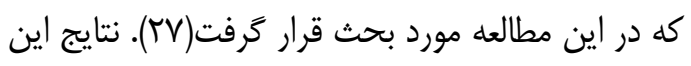

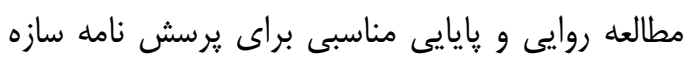

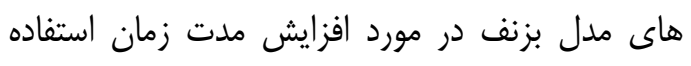

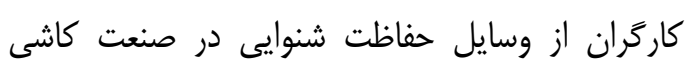

$$
\text { فراهم نموده است. }
$$

\section{بحث و نتيجه كيرى}

هدف از تحقيق حاضر بررسى روايى و وِيايايى ندي

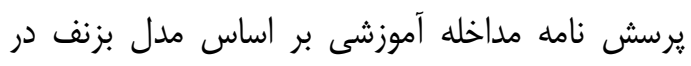

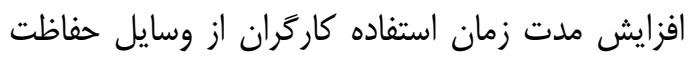

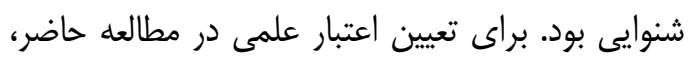

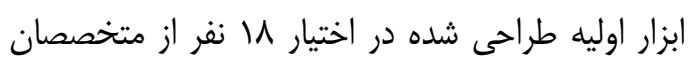

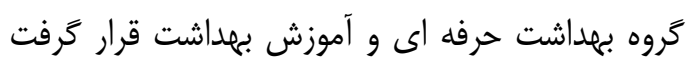
كه يكى از محاسن مطالعه مى باشد زيرا در بيشتر

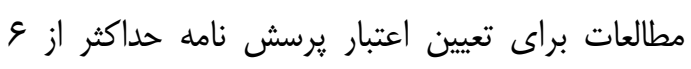

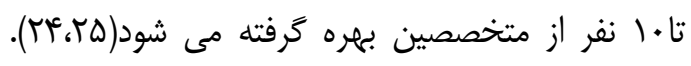

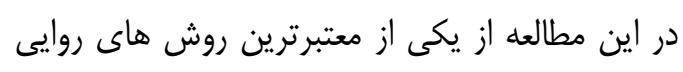

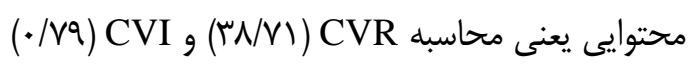
استفاده گَرديد و مقدار CVI يرسش محاسيه نامه نهايى نشان

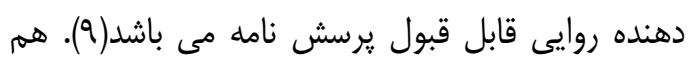

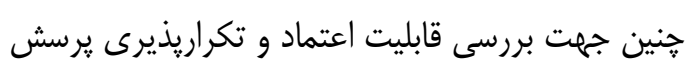

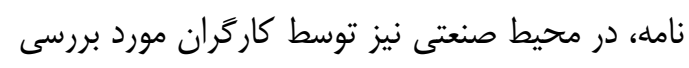

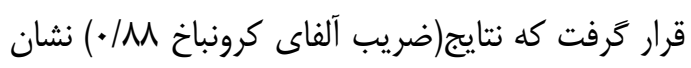




$$
\begin{aligned}
& \text { مى داند كه از متخصصان خبره و كارگرانى كه در } \\
& \text { انجام هر خه بهتر طرح يزوهشى همكارى لازم نمار نمودند، } \\
& \text { تشكر و قدردانى نمايد. }
\end{aligned}
$$

\section{References}

1.Ferrite S, Santana V. Joint effects of smoking, noise exposure and age on hearing loss. Occup Med2005;55:48-53.

2.Mirmohammadi J. Baba Haji Meibodi F, Nourani F. Investigating the hearing tolerance in the workers of the tile factory complex of Meybod. J ShahidSadoughi Uni Med Sci2008;16:8-13.

3.Ahmed H, Dennis J, Badran O, Ismail M, Ballal S, Ashoor A, et al. Occupational noise exposure and hearing loss of workers in two plants in eastern Saudi Arabia. Ann Occup Hygiene2001;45:371-80.

4.Behnood FFE. Study of protective devices and effective parameters on Hamadan province workers community 2002-2003. Hamadan J2003;2:21-6.

5.Ologe FE, Akande TM, Olajide TG. Noise exposure, awareness, attitudes and use of hearing protection in a steel rolling mill in Nigeria. Occup Med2005;55:487-9.

6.Williams W. Is it reasonable to expect individuals to wear hearing protectors for extended periods? Int J Occup Safety Erg 2009;15:175-81.

7.Health standards for occupational noise exposure final rule. Mine Safety Health Adm1999;64:49548-634.

8.Ajzen I, Fishbein M. Attitude behavior relations a theoretical analysis and review of empirical research. Psychol Bulletin1977;84:888.

9. Yaghmale F. Content validity and its estimation. J Med Edu2009;3:63-9.

10.Froman RD, Schmitt MH. Thinking both inside and outside the box on measurement articles. Res Nurs Health2003;26:335-6.

11.Ong SF. Constructing a survey questionnaire to collect data on service quality of business academics. Int J Nurs Stud2012;5:42-7.

12.Norland EVT. Controlling error in evaluation instruments. J Ext1990;28:56.

13.Bolarinwa OA. Principles and methods of validity and reliability testing of questionnaires used in social and health science researches. Nigerian Post Med J2015;22:195.

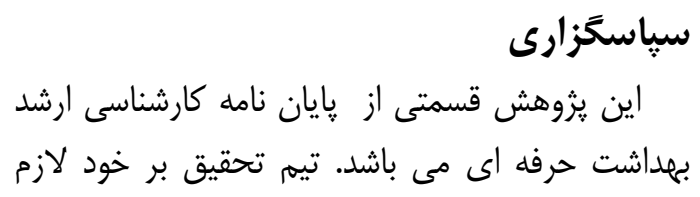

14.Thomas JR, Silverman S, Nelson J. Research methods in physical activity. 7E Hum Kin2015;2:32-8.

15.Miller M. Graduate Research Methods. Last Acc 2012;7:23-7..

16.Bolenius K, Brulin C, Grankvist K, Lindkvist M, Soderberg J. A content validated questionnaire for assessment of self reported venous blood sampling practices. BMC Res Notes2012;5:39.

17.Sangoseni O, Hellman M, Hill C. Development and validation of a questionnaire to assess the effect of online learning on behaviors attitudes and clinical practices of physical therapists in the united states regarding evidenced-based clinical practice. Int $\mathbf{J}$ All Health Sci Prac 2013;11:7.

18.Last JM. Making the dictionary of epidemiology. Int J Epidemiol1996;25:1098-101.

19.Lawshe $\mathrm{CH}$. A quantitative approach to content validity. Pers Psychol1975;2856375.

20.Leung SF, Arthur D. The alcohol use disorders identification test validation of an instrument for enhancing nursing practice in Hong Kong. Int J Nurs Stud2000;37:5764.

21.Devon HA, Block ME, Moyle P, Ernst DM, Hayden SJ, Lazzara DJ, et al. A psychometric toolbox for testing validity and reliability. J Nurs Schol2007;39:15564.

22. Yaghmaei F. Measuring behavior in research by valid and reliable instruments. Tehran Shaheed Beheshti Uni Med Sci Health Serv 2007;2:58.

23.Hyrkas K, Appelqvist K, Oksa L. Validating an instrument for clinical supervision using an expert panel. Int $\mathbf{J}$ Nurs Stud2003;40:619-25.

24.Ip WY, Chan D, Chien WT. Chinese version of the childbirth self-efficacy inventory. JAdv Nurs2005;51:625-33.

25.Karimy M, Niknami S, Heidarnia A, Hajizadeh I. Assessment of knowledge, health belief and patterns of cigarette 
smoking among adolescents. J Fasa Uni Med Sci2011;1:142-8.

26.Kline R. Nunnally, JC, Bernstein IH 1994. Psychometric theory. J Psychoedu Ass1999; 17:275-80.
27.Litwin MS, Fink A. How to measure survey reliability and validity. Sage 1995;5:32-7. 


\title{
Designing and Determination of Validity and Reliability of the Questionnaire Increasing the Duration of using the Hearing Protection Device by Workers based on BASNEF Model
}

\author{
Monazzam $M^{1}$, Laal $F^{2}$, Vali $S^{3}$, Fallahmadvari ${ }^{4 *}$, Najafi $K^{1}$, Fallahmadvari $A^{4}$
}

(Received:

Accepted: ）

\begin{abstract}
Introduction: After the engineering noise control and management control, the last way for controling noise is using the hearing protective devices, whose effectiveness depends on full-time use of it. Due to the lack of a standard questionnaire about increasing the duration of workers' usage of hearing protection devices based on BASNEF behavioral pattern, this study has been done to design and measures this tool psychometrically.
\end{abstract}

Materials \& method: The initial questionnaire of this study is drawn out of the texts, similar articles, and questionnaires. Face Validity and Content validity are measured by Lavsheh method based on obtaining the view of experts' panel and the reliability was done by cronbach's alpha coefficient by tile industry workers. All analyses were performed using 19 SPSS software.
Findings: face validity and content validity of 49 items were identified. In professional content evaluation, CVR of items up to $60 \%$ were selected and the CVI of the remaining questions became $0.79 \%$. The reliability of each of below indexes was approved as follow: knowledge: $82 \%$, attitude: 88\%, abstract norms: $83 \%$, enabling factors: $88 \%$, behavioral intention: $96 \%$ function: $89 \%$ and the overall reliability of research tool were approved by measuring Cronbach's alpha as $88 \%$.

Discussion \& Conlusions: vThese results introduced good evidence about the validity and the reliability of measurement tools on BASNEF model in increasing duration of workers usage of hearing protection devices.

Keywords: BASNEF model, Questionnaire validity reliability, Hearing protection devices

\footnotetext{
1.Dept of Occupational Health Engineering, Faculty of Public Health, Tehran University of Medical Sciences, Tehran, Iran

2. Health Promotion Research Center, Zahedan University of Medical Sciences, Zahedan, Iran

3. Student Research Committee, Faculty of Public Health, Gonabad University of Medical Sciences, Gonabad, Iran

4. Student Research Committee, Faculty of Public Health, Shahid Sadoughi University of Medical Sciences, Yazd, Iran

*Corresponding author Email: Fallah134@yahoo.com
}

\section{Scientific Journal of Ilam University of Medical Sciences}

